Article

\title{
Monitoring and Assessing Post-Disaster Tourism Recovery Using Geotagged Social Media Data
}

\author{
Yingwei Yan *, Melanie Eckle, Chiao-Ling Kuo, Benjamin Herfort, Hongchao Fan and \\ Alexander Zipf \\ Institute of Geography, Heidelberg University, 69120 Heidelberg, Germany; eckle@uni-heidelberg.de (M.E.); \\ kuo@chiaoling.com (C.-L.K.); herfort@uni-heidelberg.de (B.H.); hongchao.fan@uni-heidelberg.de (H.F.); \\ zipf@uni-heidelberg.de (A.Z.) \\ * Correspondence: Yingwei.Yan@uni-heidelberg.de or yanyingwei@u.nus.edu; Tel.: +49-6221-54-5509
}

Academic Editors: Marguerite Madden and Wolfgang Kainz

Received: 27 January 2017; Accepted: 27 April 2017; Published: 3 May 2017

\begin{abstract}
Tourism is one of the most economically important industries. It is, however, vulnerable to disaster events. Geotagged social media data, as one of the forms of volunteered geographic information (VGI), has been widely explored to support the prevention, preparation, and response phases of disaster management, while little effort has been put on the recovery phase. This study develops a scientific workflow and methods to monitor and assess post-disaster tourism recovery using geotagged Flickr photos, which involve a viewshed based data quality enhancement, a space-time bin based quantitative photo analysis, and a crowdsourcing based qualitative photo analysis. The developed workflow and methods have also been demonstrated in this paper through a case study conducted for the Philippines where a magnitude 7.2 earthquake (Bohol earthquake) and a super typhoon (Haiyan) occurred successively in October and November 2013. In the case study, we discovered spatiotemporal knowledge about the post-disaster tourism recovery, including the recovery statuses and trends, and the photos visually showing unfixed damages. The findings contribute to a better tourism rehabilitation of the study area.
\end{abstract}

Keywords: tourism; post-disaster recovery; geotagged social media data; Flickr; volunteered geographic information (VGI); data quality; space-time bin; crowdsourcing

\section{Introduction}

In recent years, geotagged social media data, as one of the forms of volunteered geographic information (VGI) [1], has been put forward to the research frontier with regard to disaster management [2]. Such data are of the merits of being rich in data coverage and volume, cost-effective, and timely, which has been widely explored for the prevention, preparation, and response phases of the disaster management cycle [3,4]. However, it has rarely been explored for the recovery phase. This study explores social media data to assist post-disaster tourism recovery. It develops a scientific workflow and methods to monitor and assess post-disaster tourism recovery using geotagged Flickr photos, which involve a viewshed based data quality enhancement, a space-time bin based quantitative photo analysis, and a crowdsourcing based qualitative photo analysis for revealing recovery statuses and trends. The developed workflow and methods have also been demonstrated in this paper through a case study conducted for the Philippines where a magnitude 7.2 earthquake (Bohol earthquake) and a super typhoon (Haiyan) occurred successively in October and November 2013. Spatiotemporal characteristics of the tourism recovery in the study area have been discovered.

Insights into utilizing the social media data to support tourism rehabilitation contribute to the decision-making for rebuilding the attractiveness of an affected tourist destination. They also contribute to consumer confidence rebooting, which is highly important to the health or even survival of the 
tourism industry. Indeed, tourism is one of the most economically important industries over the world; it is, however, vulnerable to disaster events [5-7]. In general, the tangible or physical damages to a destination (e.g., destroyed infrastructure) can be restored over time. The greater challenge, however, rests in recovering the tarnished image and reputation of a destination, which otherwise may be destroyed permanently [8]. This is due to the fact that the attractiveness of a tourist destination highly depends on tourists' perceptions with regard to its image and reputation [6,9]. Consequently, tourism is often not able to recover as fast as other businesses do.

Realizing post-disaster recoveries oftentimes require considerable financial, manpower, and intellectual investments [5,10], during the processes of which monitoring and assessing the recoveries demand special attention [11]. In general, this is due to the limited resources that can be invested [11]. For tourism in particular, distant tourists may be hesitant to visit affected destinations even if the destinations have been physically fully recovered, because they lack credible and up-to-date information regarding the recovery statuses [12]. To monitor and assess post-disaster recovery, traditional strategies include but are not limited to ground survey and observation, social audit (key informant interview, focus group), household survey, and satellite imagery analysis [11]. However, on the one hand, approaches like survey and social audit are labor-intensive, costly, and time-consuming, especially when a constant flow of information is needed from a large region (some affected areas are often inaccessible and insecure) [11]. On the other hand, approaches like remote sensing fail to capture tourist quantities, which only reveal physical reconstruction statuses (e.g., building and road reconstructions). In addition, images with high spatial and temporal resolutions normally are expensive.

Alternatively, social media data has the potential to compensate for these shortcomings. Of the three sources of social media feeds (i.e., Twitter, Flickr, Facebook) that are discussed frequently in the GIScience community, Flickr (a photo-based social network) offers the highest accessibility. It is possible to access the full stream of Flickr photos through its application programming interface (API) [13]. Twitter's API returns a small sample of the full stream (with a size of one percent), which requires a persistent connection to its server, so that obtaining long-term historical Twitter data is less possible [14]. Facebook is even more restricted on obtaining its users' data contributions [15]. Additionally, monitoring and assessing the recovery of a tourist destination is interested in people being in the field providing eye-witness information, which allows qualitative interpretations of the captured and surrounding environments. Therefore, Flickr is adopted in this study.

The remainder of this article is organized as follows. Section 2 briefly reviews some related work. Section 3 presents the workflow and methods. Section 4 presents the case study. Section 5 discusses our research outcomes and the related future work. Lastly, Section 6 concludes this article.

\section{Related Work}

\subsection{Geotagged Social Media Data for Disaster Management}

Geotagged social media data, as one of the various sources of VGI, has been widely explored in various application domains, such as people's travel patterns or human mobility [16,17], socioeconomic patterns [18], and road map inference [19]. The explorations imply the great potential of social media data in answering scientific inquires.

Particularly, an effective management of natural disaster events relies on the immediacy and currency of geospatial information collected as inputs for relevant agency decision-making, which stresses the value of VGI in all phases of the disaster management cycle (i.e., prevention, preparation, response, and recovery) [4]. Geotagged social media data has therefore been explored to support the management of both those highly harmful ones (e.g., floods, earthquakes, fires, tsunamis, and typhoons), and those relatively less attended ones such as landslides. For example, De Albuquerque et al. [20] investigated flood-related Tweets in Germany for the sake of both response and preventive monitoring. Zook et al. [21] discussed how Twitter assisted the aftermath rescue of 2010 Haitian 
earthquake. Flickr photos were also adopted as an alternative to official sources to inform the public during the 2007 Zaca wildfire in Southern California as described by Goodchild and Glennon [2]. Regarding tsunamis, Peary et al. [22] discussed the potential of utilizing social media in the related preparedness and response by public, civil society, and government organizations in Japan. Takahashi et al. [23] explored how people communicated using Twitter during the immediate aftermath of typhoon Haiyan, which pummeled the Philippines in 2013. In addition, Pennington et al. [24] explored the use of social media for data acquisition for the British Geological Survey National Landslide Database.

These explorations to a great extent represent the belief that disaster management can benefit from the collection and analysis of social media feeds. Despite these studies, they mostly focus on the prevention, preparation, and response phases of disaster management. The research community has rarely explored social media data for the recovery phase.

\subsection{Traditional Approaches for Monitoring and Assessing Post-Disaster Recovery}

Post-disaster recovery can be defined as bringing the conditions of affected areas back to a certain level of acceptability through the development and implementation of strategies and actions for rectifying damages [5]. The recovery may immediately follow the occurrence of a disaster or start from a time when the destination is able to receive assistance. The Federal Emergency Management Agency in the United States manages the aftermath of a disaster with three stages: (1) Emergency response (twenty-four hours to two or three weeks); (2) Relief (a week to half a year); and (3) Recovery (several weeks to ten years) [25].

Researchers have adopted a variety of methods to monitor and assess post-disaster recovery. For example, Hoshi et al. [26] monitored and assessed the Pisco urban recovery after the 2007 Peru earthquake using satellite images. Brown et al. [27] investigated the recovery status after the 2008 Wenchuan earthquake in China based on both satellite images and field surveys (capturing detailed georeferenced records of the recovery through photographs, video, and observations). Resident interviews have also been used as a method to monitor and assess the recovery of Punta Gorda (Florida, the United States) after hurricane Charley in 2004 [28]. McCarthy and Hanson [29] compiled and analyzed authoritative building permit data, census, and damage assessment data for three counties hit by the 2005 hurricane Katrina in the United States to describe the degree of their housing recovery. Moreover, Platt, Brown and Hughes [11] discussed a range of approaches (e.g., satellite imagery analyses, field surveys and observations, social audits, household surveys, official publications and statistics, outsourced data, and insurance data) to examine the recovery of Ban Nam Khem, Thailand from the 2004 Indian Ocean tsunami and Muzaffarabad, Pakistan from the 2005 Kashmir earthquake.

However, approaches like survey, social audit, and interview are labor-intensive, costly, and time-consuming, especially when a constant flow of information is needed from a large region (some affected areas are even difficult and insecure to access after a disaster) [11]. In addition, most published information is unavailable on a small scale [11]. Approaches like remote sensing fail to capture tourist quantities, which only reveal physical reconstruction statuses (e.g., building and road reconstructions). Satellite images with high spatial and temporal resolutions are also expensive. Although the International Charter makes some satellite data available to support disaster responses at no cost, it does not offer the data to support post-disaster recovery [30]. On the contrary, "on the ground" citizens may provide timely, cheaper, and in-suit information.

\section{Monitoring and Assessing Post-Disaster Tourism Recovery Using Geotagged Flickr Photos}

Given the limitations of the traditional approaches for monitoring and assessing post-disaster recovery, and the lack of attention to utilizing social media in this field, we aimed to contribute to the filling of such research gaps. In this section, we present a workflow and methods to utilize geotagged Flickr photos for monitoring and assessing post-disaster tourism recovery, which are outlined in Figure 1. There are three steps after the retrieval of Flickr photos and their metadata through Flickr 
API (https:/ /www.flickr.com/services/api/). Step one is quality enhancement, which is a preparatory step for the subsequent steps. VGI's heterogeneity, diversity, lack of adherence to standards required in the creation of conventional authoritative data (e.g., government generated data), and lack of data descriptions for determining its fitness for a particular purpose [31], result in the importance of VGI quality enhancement before using them for any further analysis. Specifically, we incorporate the enhancement of locational accuracy and thematic accuracy (i.e., discriminating tourist photos from non-tourist photos) into the workflow. Step two is quantitative tourist photo analysis. This step performs space-time analysis of the tourist photos that resulted from step one. The last step is to qualitatively investigate the visual contents of all available photos (regardless of whether a photo is a tourist photo or not) that resulted from step one, in order to dig up those showing the reconstruction status of an affected tourist destination. The following sub-sections will describe the workflow and methods in detail.

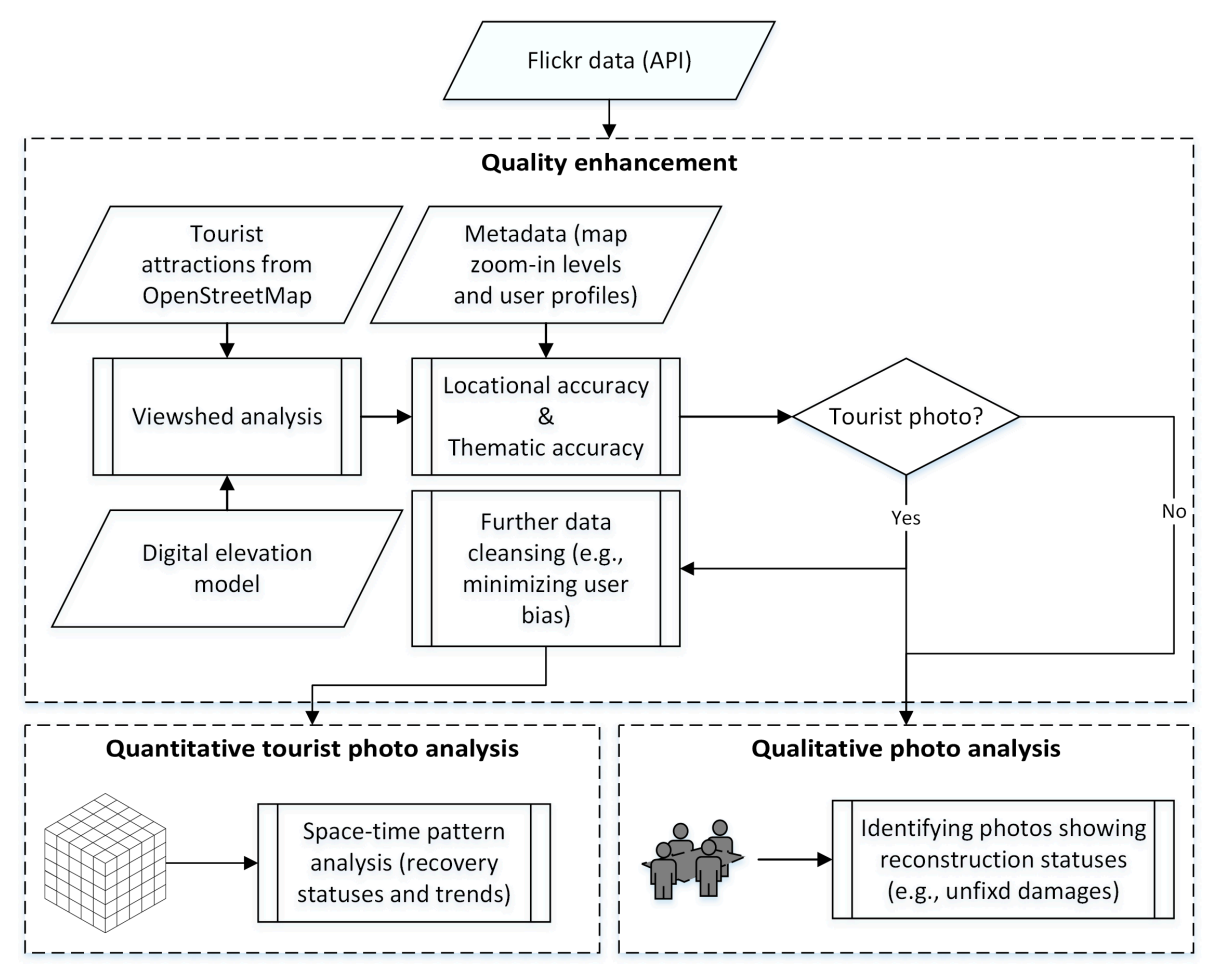

Figure 1. The outline of the developed workflow and methods for monitoring and assessing post-disaster tourism recovery using geotagged Flickr photos.

\subsection{Quality Enhancement}

The tourist sites of a study area can be extracted from OpenStreetMap, namely, retrieving the features with tags related to tourism. For OpenStreetMap, being a VGI project, its data quality is expected to be high in general in regions with an active mapping community [32]. With the tourist sites obtained from OpenStreetMap, we can conduct a viewshed analysis using a digital elevation model covering the study area [13]. Based on terrain characteristics (e.g., whether there exist mountain barriers), a viewshed analysis informs us where people can see at least one of the tourist sites of the study area. Such an analysis can be conducted using the Viewshed tool of ArcGIS (ESRI Products, Redlands, CA, USA). Therefore, on the one hand, the viewshed analysis enables us to remove those photos that are probably incorrectly positioned (i.e., those tourist photos located at positions from where no tourist site can actually be seen); and, on the other hand, enables us to enhance the thematic relevancy of the photos to tourism (i.e., only retaining photos within the viewshed area of tourist sites). Additionally, the map zoom-in levels for positioning Flickr photos after being taken by users 
vary between 1 and 16 (world level is 1 , country $2-3$, region $4-6$, city $7-11$, street $12-16$ ). Working only on those street-level photos ensures the highest locational accuracy. Second, to further ensure the relevancy of retrieved Flickr photos to tourism, we classify the photos into tourist versus non-tourist ones based on user profiles (i.e., determining whether a user is a tourist or not based on where he or she resides). Lastly, before conducting quantitative photo analysis, further data cleansing is necessary depending on the characteristics of retrieved Flickr dataset. For example, some extremely active users may contribute many more photos than other users do. The photos from such users should be treated with caution, for avoiding possible bias towards such users (see our case study as follows as an example).

\subsection{Quantitative Tourist Photo Analysis}

The second analytic step is to quantitatively analyze the tourist photos that resulted from the abovementioned quality enhancement step, which enables the derivation of photo flow patterns as an indicator for tourism recovery status. Post-disaster recovery has been shown to vary over space and time due to socioeconomic and political factors and a variety of decisions that have been made throughout the disaster management cycle [25]. Therefore, speaking of monitoring and assessment of a post-disaster tourism recovery, the spatiotemporal patterns of the recovery are perhaps the top concern of stakeholders. We put forward a space-time bin method (adapted from [33]) to analyze tourist photos in both spatial and temporal dimensions. As illustrated in Figure 2, a study area is first divided into a certain number of tiles (cells). Note that the determination of the tile size is context-dependent (see how we determined the tile size in our case study below as an example). A bin is formed when temporal dimension has been incorporated into a tile as the height of the bin. Each bin aggregates the data from a single tile location and a single time period. The bins within the same time period form a bin slice, and the bins overlapping on a single tile location form a bin time series. Bin slices and bin time series can extend infinitely before reaching the boundary of the study area and the time needed for recovery, respectively. The advantage of using the space-time bins to encapsulate data is that it allows us to easily perform three-dimensional comparisons among data. For instance, to examine the spatiotemporal patterns of tourist photo flows, two types of analysis are considered in our work: (1) similarity analysis; and (2) post-disaster trend analysis.

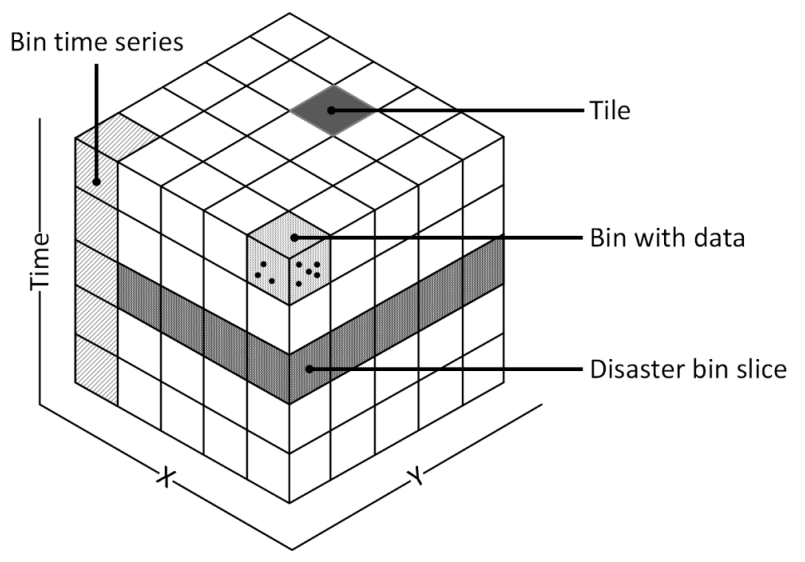

Figure 2. Space-time bin for data aggregation (adapted from [33]).

Similarity analysis is concerned with the similarity between a post-disaster bin or bin time series (with data) and its pre-disaster counterpart. For example, assuming that we have bins that aggregate tourist photos yearly, one may simply examine to what degree the total number of photos that contributed in a post-disaster year is close to that in the year before the disaster (as an indicator for the degree to which a post-disaster tourism is similar to its pre-disaster state). However, such an analysis is probably only suited to study areas of which the tourism does not depend on seasonality. 
For areas with seasonal changes that affect the tourism, the tourism recoveries may vary over different seasons. It leads to bias towards those leading seasons in the recoveries if we simply compare the yearly sums. One better way of conducting the similarity analysis is through a month-based analysis. Assuming that we have bins that aggregate tourist photos monthly, such an analysis can be conducted that measures the similarity between the monthly photo quantities for a year after a disaster and the corresponding monthly photo quantities for the year before the disaster. To do that, the modified Jaccard similarity index which ranges from zero to one (greater value represents higher similarity) [34] is adopted in our work. In the case of month-based photo quantity analysis, the computation of this index takes not only the total numbers of photos contributed in two comparative years but also the total number of photos contributed during individual months of the two comparative years into account (see our case study as an example). The index is expressed using Equation (1):

$$
J_{i}=\frac{\sum_{j=1}^{12} \min \left(a_{i, j}, b_{i, j}\right)}{\sum_{j=1}^{12} a_{i, j}+\sum_{j=1}^{12} b_{i, j}-\sum_{j=1}^{12} \min \left(a_{i, j}, b_{i, j}\right)},
$$

where $a_{i, j}$ is the total number of tourist photos contributed during month $j$ (e.g., January, February) at tile $i$ in a post-disaster year; $b_{i, j}$ is the total number of tourist photos contributed during month $j$ at tile $i$ in a pre-disaster year.

In addition, post-disaster trend analysis examines whether the quantities of user contributions within a post-disaster bin time series is with an upward trend, downward trend, or flat trend, as an indicator for tourism recovery trend (in recovery, or recession, or stagnation). For example, assuming that we have bins that aggregate tourist photos monthly, such an analysis can be conducted that investigates the trend of the monthly photo quantities for a number of successive months (e.g., 24 successive months) after a disaster. However, it is also necessary to take seasonality into account for tourism that highly depends on seasonal variations. In such cases, we can group the monthly bins from individual post-disaster years based on seasonality, so as to obtain seasonal bin time series (e.g., summer bin time series). Subsequently, we can combine the seasonal bin time series from several successive post-disaster years, and analyze the trend of the monthly photo quantities within the combined bin time series (see our case study as an example). The Mann-Kendall trend test [35] describes the trend in a series of values, which is therefore adopted for the trend analysis.

\subsection{Qualitative Photo Analysis}

Not only making sense of the quantity of tourist photos may generate insights into the recovery status of a disaster-affected tourism, but also qualitatively examining the visual contents of both tourist and non-tourist photos can be informative for decision-makers. This practice has already been proved to be of great potential for generating situational awareness in disaster responses [36]. In the recovery phase, we may be able to dig up photos showing, for example, the reconstruction status of an affected tourist destination (e.g., detecting unfixed damage that may affect the tourism), and inform tourists or disaster managers for decision-making. Image content recognition could be a tedious task, as the quantity of photos retrieved from a disaster-affected area can be huge. Therefore, we incorporate a crowdsourcing-based image content recognition process into the workflow, which can be readily set up with off-the-shelf web-based crowdsourcing platforms (e.g., pybossa, http://pybossa.com/). This method has also been used in [36].

\section{Case Study}

\subsection{Study Area}

The study area is the central Philippines islands region (Figure 3), which is a popular tourist destination with culture and religious heritage, a diversity of plants, animals, geological wonders, beaches, diving sites, and resorts. Regarding seasonal characteristics, the study area is located in the 
tropical zone, of which the seasons are not characterized by spring, summer, autumn, and winter. It, however, has dry seasons and wet seasons that result in the high and low seasons of its tourism. According to [37], the yearly high season of the tourism in the study area ranges from December to April because of the cooler and pleasant weather, while the low season ranges from May to November due to the hot temperatures and high rainfall amounts, and even extreme weather such as torrential downpours and typhoons.

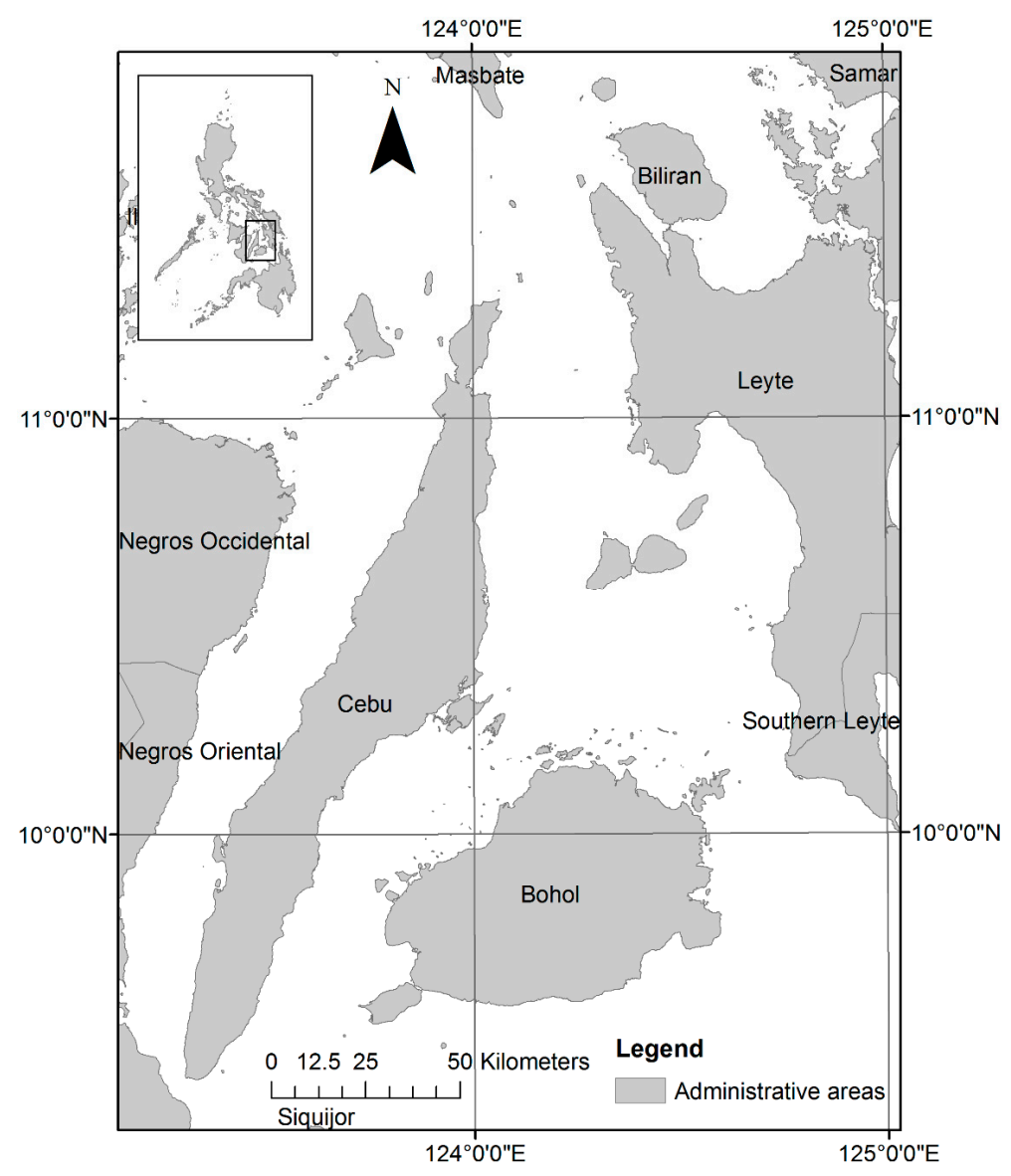

Figure 3. Study area. The central Philippines islands region.

Unfortunately, the area was devastated by a magnitude 7.2 earthquake (Bohol earthquake) and a super typhoon (Haiyan) on 15 October 2013 and 8 November 2013, respectively [38,39]. The twin disasters led to extreme loss of life and widespread damage to the infrastructure and natural landscapes. The tourism industry of the area has therefore been strongly affected, making it an ideal study area for us to monitor and assess its post-disaster tourism recovery. According to news media, slow progress of government response to the post-disaster recovery has been reported even after one year since the disasters [40]. Many tourists were hesitant to visit the islands, due to their perception that the islands were not ready for tourists [41]. Although full recovery is still underway, there could be leading areas that have recovered first and have geared up to accommodate guests [41]. Therefore, this case study utilizes the above introduced workflow and methods to monitor and assess the post-disaster tourism recovery of the study area by making sense of Flickr photos.

\subsection{Data Collection and Pre-Processing}

Following the access policies and regulations of Flickr API, we developed a tool based on a PHP script to collect Flickr photos and their metadata. The tool retrieves Flickr data by scanning the study area using a 0.5 degree by 0.5 degree moving window, starting from the upper left corner. Since the 
Flickr API allows for accessing a maximum of 4000 photos in a single API query execution, a window is subdivided into four equal-sized sub-windows in case more than 4000 photos are contained within that window. This subdivision is recursively performed until no API query returns more than 4000 photos. For the case study, using the tool, we collected 71,329 geo-tagged (WGS 84 bounding box: 123.220, 9.371, 124.696, 11.604) time-stamped (ranging from 1 April 2004 to 6 July 2016) Flickr photos contributed by 3790 users (Figure 4). Although the disasters occurred in 2013, we collected all historical photos dating back to the startup of Flickr, which were beneficial for the tourist versus non-tourist photo classification (see the classification details below).
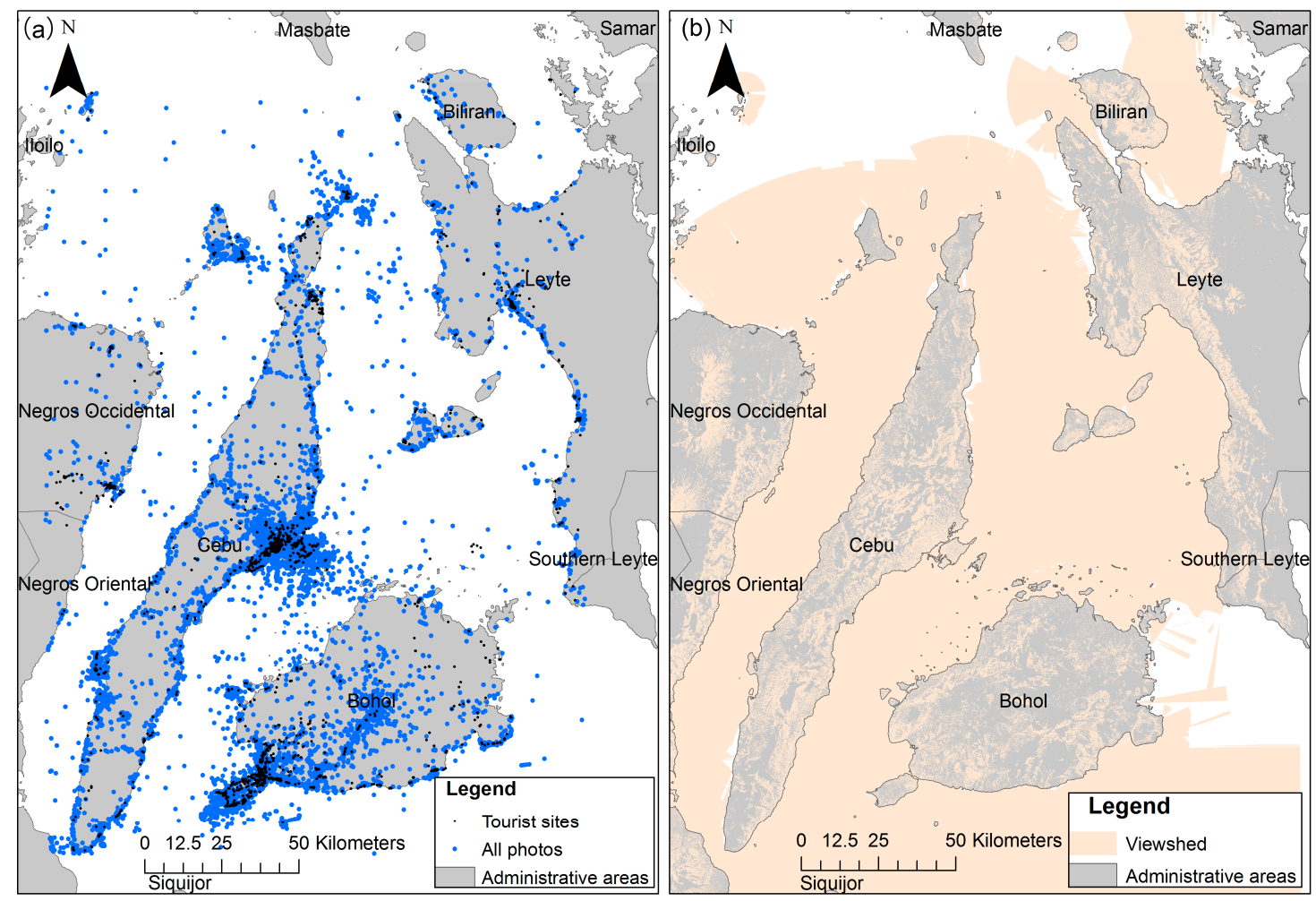

Figure 4. (a) The spatial distribution of the initially retrieved Flickr photos and the tourist sites; (b) the viewshed area of the tourist sites, from where people can see at least one of the tourist sites.

With the collected photos, a viewshed analysis was first conducted using the Viewshed tool of ArcGIS 10.4.1 with tourist sites locations extracted from OpenStreetMap and ASTER GDEM 2 data [42] obtained from USGS's earth explorer [43]. We extracted all features (1477 point features, one line feature, and 573 polygon features) with tourism, historic sites, and places of worship related tags from OpenStreetMap as the tourist sites. The point features and the mean centers of the polygon and polyline features were used as the inputs of the viewshed analysis. OpenStreetMap mapping in the Philippines has been ongoing since 2006, which has been constantly developing thanks to a growing Filipino mapping community continuing to add to, edit, and validate the data [44]. Moreover, the study area has been covered in the mapping tasks of the Humanitarian OpenStreetMap Team after typhoon Haiyan in 2013, and the related map products have already been used on the ground by aid agencies such as the American Red Cross [45]. This high interest in the Mapping leads to the assumption that the OpenStreetMap data in the study area can be expected to be of a good level of quality. Regarding ASTER GDEM 2 ( $30 \mathrm{~m}$ by $30 \mathrm{~m}$ cell size), this digital elevation model data includes building and canopy heights, rather than the "bare Earth", which is necessary in the context of this study as users may climb to the top of buildings to take photos. The viewshed area of the tourist sites is shown in Figure $4 \mathrm{~b}$ in light brown color, and photos located outside the light brown colored area 
were removed. After the viewshed analysis, 49,608 photos were retained, of which we further removed 13,242 non-street-level photos (36,365 photos left).

The next step was to classify the remaining 36,365 photos into tourist and non-tourist photos based on where the users reside. A user living outside the study area was considered as a tourist. Note that approximately $30 \%$ of the 36,365 photos lacked information about where the contributors live, which were manually classified based on the photos' visual contents. That is, a user was classified as a tourist if most of the photos contributed by this user could be visually recognized related to tourism (e.g., sightseeing), and then all the photos from the user were classified as tourist photos. Indeed, it was observed that most of the photos contributed by non-tourists (locals) were about the activities of their daily lives (e.g., parties, friend or family gatherings). This was also the reason we collected all historical photos through Flickr's API, the more the photos from a user were available for the tourist versus non-tourist recognition, the easier the recognition would be. The classification results showed $71.2 \%$ tourist photos, $27.4 \%$ non-tourist photos, and $1.3 \%$ unclassified photos that were the ambiguous ones (e.g., some users only uploaded photos about food, who also did not indicate where they live).

The tourist photos resulting from the viewshed analysis and photo classification are shown in Figure 5. It can be seen that the resulting tourist photos highly associate with the tourist sites (Figure 5), compared with those initial photos (Figure 4a). Those initially retrieved photos scatter around the study area, many of which are even in the middle of the ocean represented as the white area in Figure $4 \mathrm{a}$. Lastly, we noticed that $10.5 \%$ of the resulting tourist photos were contributed by one single tourist from Switzerland (extremely active compared with usual users). We removed all of the photos from this user before we conducted the quantitative photo analysis (to be introduced in the next section), in order to avoid analytic bias towards this user.

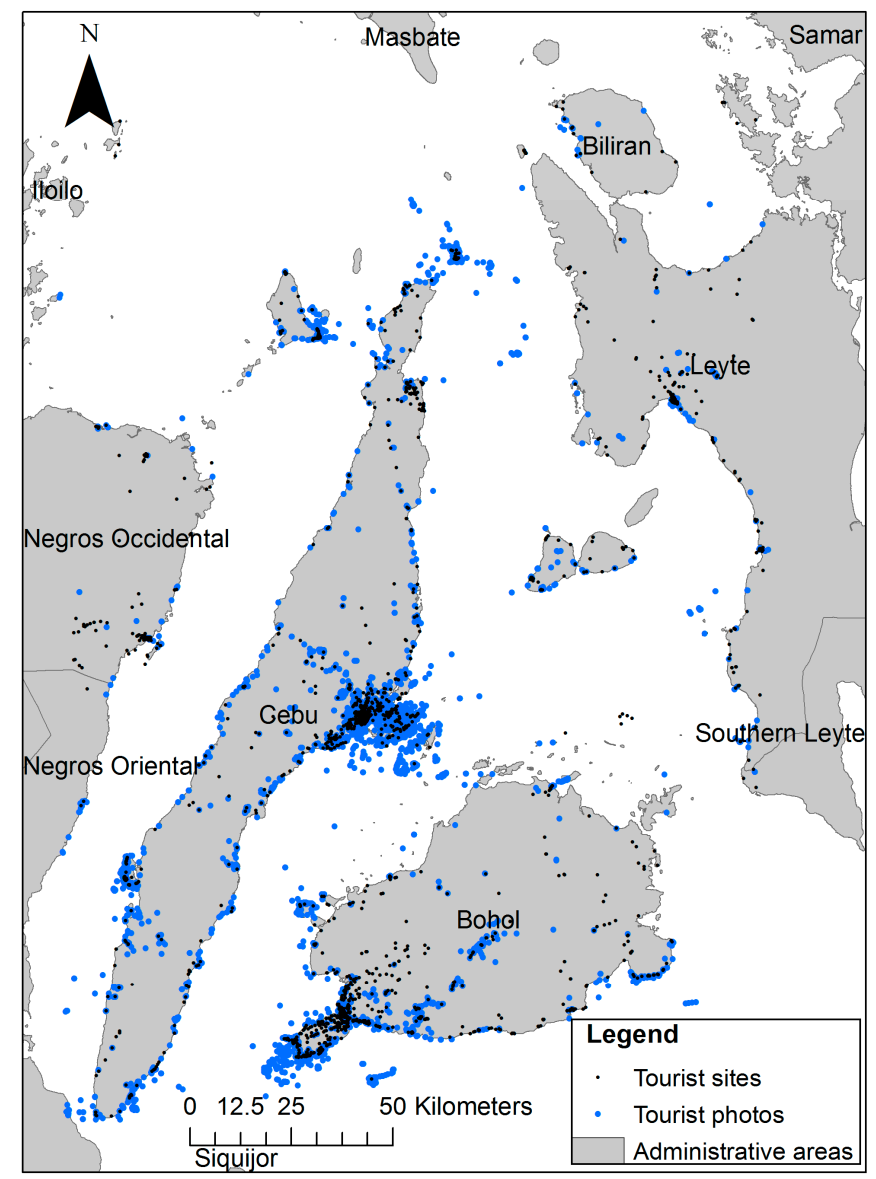

Figure 5. The tourist photos resulting from the viewshed analysis and photo classification. 


\subsection{Photo Analysis}

With the tourist photos resulting from the pre-processing, quantitative similarity analysis and post-disaster trend analysis were conducted based on the space-time bin method introduced above. A tile size of 14,465.3 $\mathrm{m}$ was adopted here, which was determined with the Calculate Distance Band from Neighbor Count tool of ArcGIS 10.4.1. In our case, given the tourist sites as the input feature class, we used the tool to calculate the distance for each tourist site to its nearest neighboring tourist site. Among the distances generated, the maximum one was used as the tile size, which ensured that every feature in the input feature class had at least one neighbor.

The similarity analysis was conducted first. Since the first year after the disasters was the transition from the response phase to the recovery phase of the disaster management [46], we compared the similarity between the bin time series for the second year after the twin disasters (from 1 October 2014 to 30 September 2015) and its counterpart for the year before the disasters (1 October 2012 to 30 September 2013). Each bin in the bin time series aggregated tourist photos monthly. The similarity was investigated using the modified Jaccard similarity index introduced above [34], considering that the tourism of the study area varies over different seasons.

The similarity analysis indicates the degree to which the tourism is similar to its pre-disaster state. However, it does not indicate the direction of the tourism recovery. A post-disaster trend analysis answers this question. Still using bins aggregating tourist photos monthly, for the two successive years after the disasters, we examined the trends of the monthly photo quantities for high seasons and low seasons of the tourism, separately. Therefore, we had two separate seasonal bin time series for each tile of the study area. In chronological order, the high season bin time series involved ten months: December 2013 to April 2014 + December 2014 to April 2015; and the low season bin time series involved 14 months: October to November 2013 + May to November 2014 + May to September 2015.

After the quantitative analyses, we further qualitatively examined the visual contents of the photos contributed during the last three months of the second year after the disasters (i.e., July, August, and September 2015, which were the three most recent bins involved in the quantitative analyses). Note that the photos we examined in this step involved all available street-level photos resulting from the viewshed analysis, regardless of whether a photo is a tourist photo or not. In this qualitative photo analysis, we aimed to identify unfixed damages that may affect the tourism. As mentioned above, a crowdsourcing-based method can be used. However, as a simplified demonstration, we did the task manually by ourselves instead of seeking help from the crowd.

\subsection{Results and Interpretations}

The similarity between the monthly tourist photo quantities of the second year after the disasters and those of the year before the disasters is shown in Figure 6. Higher similarity values are generally distributed in those relatively more popular tourist areas, such as Cebu city, Southwest Bohol province, Bantayan and Malapascua islands in the Northern Cebu (Figure 6). This observation implies that such areas are relatively more robust after the disasters, which perhaps received more attention to their restorations. Indeed, not long after the disasters, there was effort to boost the tourism of the top destinations (e.g., Cebu and Bohol) by ensuring that they remained open for business with their respective ports of entry still accessible to tourists [47]. Additionally, the Philippine Red Cross spent much effort on constructing core shelters, full houses, and structures in Bohol [48]. The regional director Rowena Lu Montecillo of the Department of Tourism Central Visayas further echoed our interpretation, who tried to convince tourists to come back by saying that some regions, for instance, Bantayan and Malapascua islands, have been ready to accommodate tourists since even the middle of 2014, although full recovery was still underway [41]. The recovery of Bantayan island even attracted volunteering support from overseas [49]. 


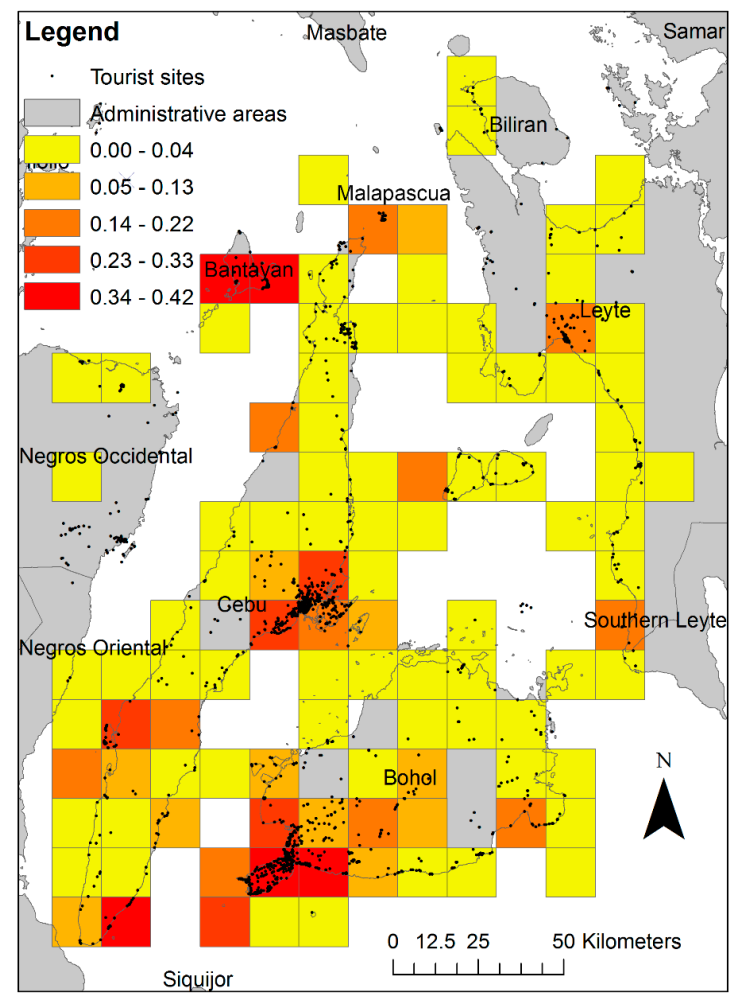

Figure 6. The similarity between the monthly tourist photo quantities of the second year after the disasters and those of the year before the disasters (only the tiles with photo contributions are shown).

The similarity map can be useful for both disaster management decision makers and tourists. The former can decide which areas need more attention for their tourism recoveries, while the latter can decide which areas can be the priorities for visiting (i.e., following preceding tourists to visit those areas that appear to be more robust after the disasters). Note that the similarity map could be qualitatively validated by 8 List [40] regarding Bohol province. 8List [40] states that Bohol's tourism has been returning to its pre-disaster state during the two post-disaster years. However, more effort is needed for the recovery, and there is indeed ongoing effort to bring Bohol back on track [40]. In fact, the restoration of Southwest Bohol province's infrastructure and historical heritage remains a work in progress after two years, although some buildings and roads have been recovered [50]. This echoes the recovery status of Bohol illustrated in Figure 6 (i.e., the illustrated similarity to the pre-disaster state).

Those areas with low similarity values need more attention to their tourism recoveries anyhow. While for those areas with relatively higher similarity values, we should not treat their recoveries lightly. Despite the higher similarity values, their tourism may be still fading out somehow. Therefore, we looked into 14 such tiles from eight areas (Figure 7) to further investigate their seasonal tourism recovery trends, the results of which is shown in Figure 8. There is no downward trend during high seasons for all of the 14 selected tiles (Figure 8), which is a good sign. This is perhaps due to the cooler and drier weather compensating for the tarnished images and reputations of the tourism. In addition, the attractive Sinulog-Santo Niño Festival is also celebrated during high seasons (on January every year). Unfortunately, we observed nine tiles suffering from downward trends, possibly due to the fact that the unfavorable weather in low seasons worsened the attractiveness of these areas. Adding the reported slow progress of government response to the post-disaster recovery after even one year since the disasters [40], tourist confidence might be even lower, and further losses of tourists could occur. Therefore, the findings imply that more effective tourism recovery tactics are needed for hotter and wetter seasons, especially for Bantayan island, Cebu city, Malapascua island, Matalom municipality, Santander municipality, and part of Southwest Bohol province. In addition, as for the 
two most popular and largest tourist destinations in the study area, namely Southwest Bohol province and Cebu city, it appears that Southwest Bohol province has recovered better than Cebu city (Figure 8). All three of the tiles covering Cebu city faced downward trends, while three out of four tiles covering Southwest Bohol province had upward trends. This is perhaps due to the perceptions of people that the infrastructure and tourist attractions of Cebu city have not fully prepared to accommodate tourists. Instead of man-made attractions, the tourism of Southwest Bohol province relies relatively more on their natural landscapes or seascapes.

Lastly, regarding the visual contents of the photos, we identified two photos showing that the restoration of the damaged Baclayon Church was still a work in progress. They were uploaded by two different tourists on 24 July 2015 (Figure 9a) and 26 July 2015 (Figure 9b), respectively, which were positioned at tile 13 in Figure 7. Indeed, it was reported that this church was devastated by the Bohol earthquake [51], and the tourists' observations have been validated by Camongol [50]. In addition, one of the two tourists also contributed a photo on 26 July 2015, further showing that the damaged seashore infrastructure near the church had not been fixed. On the one hand, these photos send a message to disaster managers about the restoration progress until 26 July 2015. On the other hand, these photos send an alert to tourists so that they can plan their sightseeing in Bohol more effectively, unless they are indeed interested in seeing the ruins. Note that we identified only three photos showing the unfixed damage illustrated in Figure 9. Other than this case study, in more developed countries with more Flickr users, it is possible that more photos (both tourist and non-tourist photos) showing various damaged properties such as recreational sites, transportation facilitates, and parks can be detected.

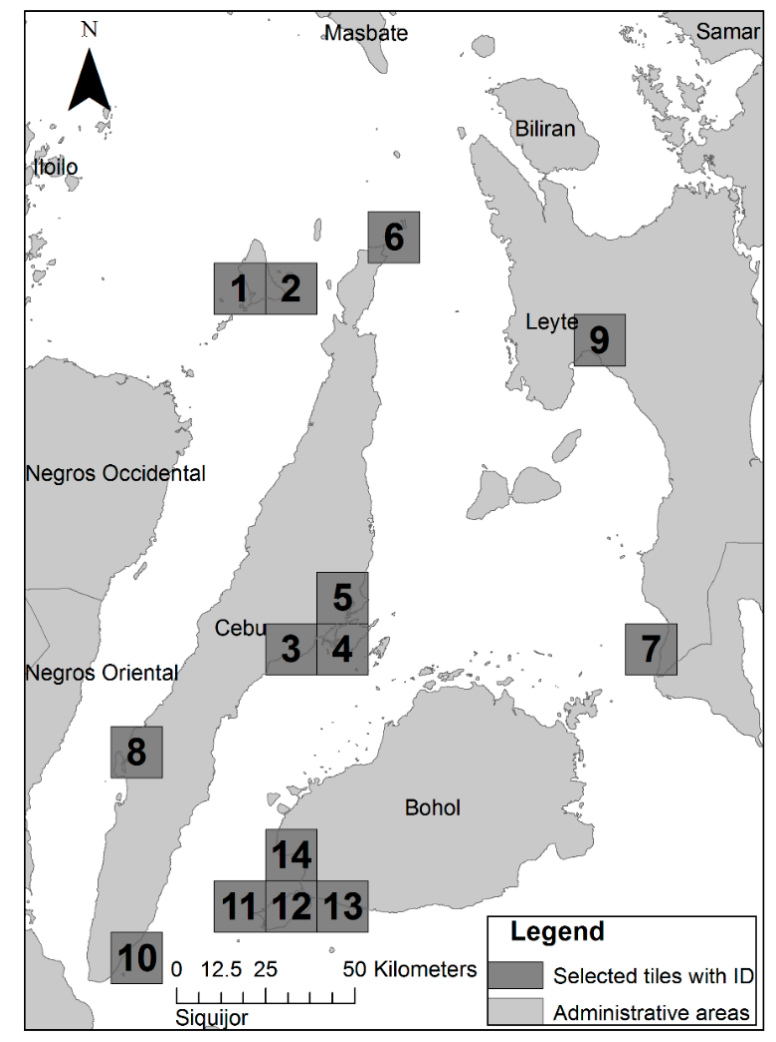

Figure 7. Fourteen tiles selected from eight areas for post-disaster trend analysis, due to their relatively higher popularity in the local tourism sector and higher similarity values generated by the similarity analysis. Identification (ID) number of the tiles are labeled using Arabic numbers. These eight areas include Bantayan island (tile IDs: 1 and 2), Cebu city (tile IDs: 3-5), Malapascua island (tile ID: 6), Matalom municipality (tile ID: 7), Moalboal municipality (tile ID: 8), Ormoc city (tile ID 9), Santander municipality (tile ID: 10), and Southwest Bohol province (tile IDs: 11-14). 


\begin{tabular}{|c|c|c|c|}
\hline Tile ID & Location & High season & Low season \\
\hline 1 & Bantayan island & & \\
\hline 2 & Bantayan island & & \\
\hline 3 & Cebu city & & \\
\hline 4 & Cebu city & & \\
\hline 5 & Cebu city & & \\
\hline 6 & Malapascua island & & \\
\hline 7 & Matalom municipality & & \\
\hline 8 & Moalboal municipality & & \\
\hline 9 & Ormoc city & & \\
\hline 10 & Santander municipality & & \\
\hline 11 & Southwest Bohol province & & \\
\hline 12 & Southwest Bohol province & & \\
\hline 13 & Southwest Bohol province & & \\
\hline 14 & Southwest Bohol province & & \\
\hline
\end{tabular}

Figure 8. Results of the post-disaster seasonal trend analysis for the 14 selected tiles. Blue color indicates an upward trend, red color indicates a downward trend, and green color indicates a flat trend.

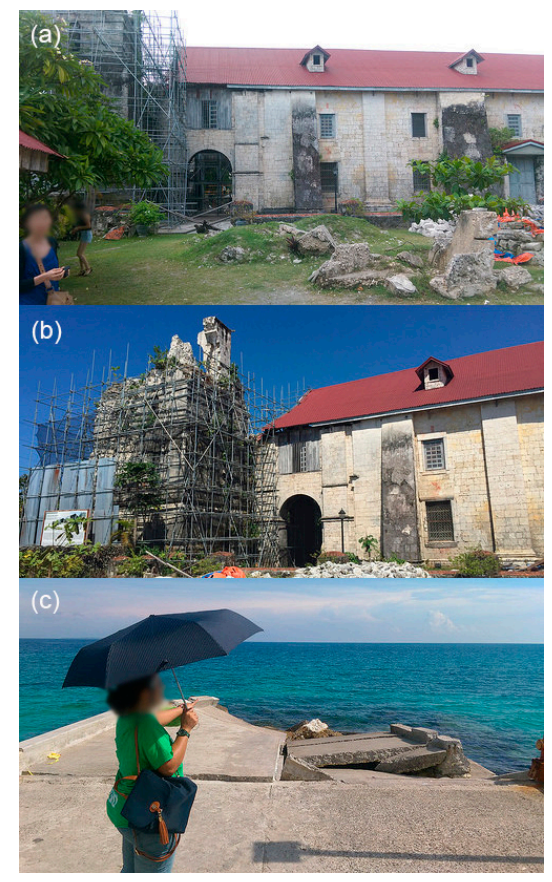

Figure 9. (a,b) Photos uploaded on 24 July 2015 and 26 July 2015, respectively, showing the reconstruction of the damaged Baclayon Church; (c) photo uploaded on 26 July 2015, showing the unfixed seashore infrastructure near the church.

\section{Discussion}

The features of social media data in monitoring and assessing post-disaster tourism recovery are manifold. First, social media data are rich in data coverage and volume, and the analysis can easily cover a large area as exemplified in our case study. Second, social media data are cost-effective, the Flickr data collected in the case study were free of charge, and the only effort required in retrieving the data was to gain necessary technical skills for using Flickr API. Third, social media data are timely. For example, Flickr data are shared continuously, which reflect the near real-time situations on the ground. In comparison to social media data, the collection of traditional data is often focused on a limited number of selected sampling sites or survey sites, which is also time-consuming due to financial and manpower constraints [11]. Although remote sensing images can cover a large area of interest, obtaining images with both high spatial and temporal resolutions normally come with high costs. It is also hardly possible to reveal tourist quantities from the images. 
Nevertheless, several pertinent issues must be pointed out. First, it should be noted that the quantity of social media contributions only implies tourist preferences of visiting during a tourism recovery process, rather than the actual status of infrastructure recovery. In fact, an area with physically well restored infrastructure but an unrestored reputation can still have a low number of tourists. Another issue of using social media data for monitoring and assessing tourism recovery is probably the related sampling bias issues. Traditional data collection methods involve scientifically pre-designed sampling strategies and strict controls during data collection processes. For example, when using a key informant interview method, investigators can select those respondents who are considered as more representative [27]. In the case of social media, the data contributors tend to be diverse and heterogeneous, and the acquisition of detailed user personal particulars are less possible. Taking the Flickr photos contributed by the non-locals in our case study as an example, it is hard to determine whether those non-local photo contributors are pure tourists or photographers who are less representative for the local tourism. In addition, there exist unequal representativeness even among pure tourists because of the unequal numbers of photo contributions from different users. Even though we can remove those extremely active users (i.e., extremely unequal representativeness, as shown in the case study), those relatively minor unequal representativeness may still be there.

Therefore, these issues point to our future work. First, although we qualitatively examined the visual contents of Flickr photos about unfixed damages, it is necessary to explore methods to further mine the qualitative metadata of Flickr photos such as user-generated captions (i.e., short descriptions) and system-generated auto-tags. These qualitative metadata could be heterogeneous [52], but mining them may generate further insights into the physical recovery status of an affected tourist destination. The second future work pertains to the mitigation of the aforementioned sampling bias issues. One potential solution is to classify photos based on user behaviors, although we classified the photos into tourist and non-tourist photos based on user profiles in the case study presented above. For example, Zheng et al. [16] introduced the concept of mobility entropy. Tourists and non-tourists may have different mobility entropies, which is the same with the case when comparing pure tourists with photographers. In addition, methods should be developed to equalize the weights of different users who contributed different numbers of photos. Apart from the future work related to Flickr photos, since it is not guaranteed that there are active OpenStreetMap mapping activities throughout the world, it will be necessary to incorporate a better way to retrieve tourist sites. It is also likely that the tourist sites extracted in our case study are incomplete, although the OpenStreetMap data in the study area can be expected to be of a good level of quality. Finally, this study privileged major tourist areas (i.e., the viewshed area of tourist sites). Some tourists may like to explore and visit areas that are far from tourist attractions, and it is worth examining how such areas recover in future work.

\section{Conclusions}

With the growing popularity of utilizing social media data to assist disaster management, the research community has rarely explored such data for the recovery phase of disaster management. This study generates insights into this line of research by creating a scientific workflow and methods to enable the monitoring and assessment of post-disaster tourism recovery based on Flickr photos. The workflow and methods have also been demonstrated through a case study conducted for the Philippines. In the case study, we discovered spatiotemporal knowledge about the post-disaster tourism recovery, including the recovery statuses and trends mined from tourist photos and photos visually showing unfixed damage from both tourist and non-tourist photos. Future work mainly includes investigating the qualitative metadata of Flickr photos, photo classification based on user behaviors, and developing methods to minimize user sampling bias. 
Acknowledgments: This research was supported by the Deutsche Forschungsgemeinschaft Initiative of Excellence, Heidelberg Karlsruhe Research Partnership (HEiKA) Programme. It was also partly supported by funding from Klaus Tschira Foundation, Heidelberg. We also acknowledge the financial support of the Deutsche Forschungsgemeinschaft and Ruprecht-Karls-Universität Heidelberg within the funding programme Open Access Publishing. We thank the Karlsruhe Institute of Technology, Geophysical Institute for the partnership in conducting this research.

Author Contributions: Yingwei Yan, Melanie Eckle, Chiao-Ling Kuo, Benjamin Herfort, Hongchao Fan, and Alexander Zipf contributed ideas to the development of the workflow and methods. Yingwei Yan, Melanie Eckle, and Chiao-Ling Kuo collected the data involved in the study. Yingwei Yan and Melanie Eckle conducted the data analyses. Yingwei Yan wrote the paper.

Conflicts of Interest: The authors declare no conflict of interest.

\section{References}

1. Goodchild, M.F. Citizens as sensors: The world of volunteered geography. GeoJournal 2007, 69, $211-221$. [CrossRef]

2. Goodchild, M.F.; Glennon, J.A. Crowdsourcing geographic information for disaster response: A research frontier. Int. J. Digit. Earth 2010, 3, 231-241. [CrossRef]

3. Horita, F.E.A.; Degrossi, L.C.; de Assis, L.F.G.; Zipf, A.; de Albuquerque, J.P. The use of volunteered geographic information (VGI) and crowdsourcing in disaster management: A systematic literature review. In Proceedings of the Nineteenth Americas Conference on Information Systems, Chicago, IL, USA, 15-17 August 2013.

4. Haworth, B.; Bruce, E. A review of volunteered geographic information for disaster management. Geogr. Compass 2015, 9, 237-250. [CrossRef]

5. Mair, J.; Ritchie, B.W.; Walters, G. Towards a research agenda for post-disaster and post-crisis recovery strategies for tourist destinations: A narrative review. Curr. Issues Tour. 2016, 19, 1-26. [CrossRef]

6. Walters, G.; Mair, J. The effectiveness of post-disaster recovery marketing messages-The case of the 2009 Australian bushfires. J. Travel Tour. Mark. 2012, 29, 87-103. [CrossRef]

7. Ryu, K.; Bordelon, B.M.; Pearlman, D.M. Destination-image recovery process and visit intentions: Lessons learned from Hurricane Katrina. J. Hosp. Mark. Manag. 2013, 22, 183-203. [CrossRef]

8. Santana, G. Crisis management and tourism. J. Travel Tour. Mark. 2004, 15, 299-321. [CrossRef]

9. Pearlman, D.; Melnik, O. Hurricane Katrina's effect on the perception of New Orleans leisure tourists. J. Travel Tour. Mark. 2008, 25, 58-67. [CrossRef]

10. Liu, M.; Scheepbouwer, E.; Giovinazzi, S. Critical success factors for post-disaster infrastructure recovery: Learning from the Canterbury (NZ) earthquake recovery. Disaster Prev. Manag. Int. J. 2016, 25, 685-700. [CrossRef]

11. Platt, S.; Brown, D.; Hughes, M. Measuring resilience and recovery. Int. J. Disaster Risk Reduct. 2016, 19, 447-460. [CrossRef]

12. Rittichainuwat, B. Ghosts: A travel barrier to tourism recovery. Ann. Tour. Res. 2011, 38, 437-459. [CrossRef]

13. Senaratne, H.; Bröring, A.; Schreck, T. Using reverse viewshed analysis to assess the location correctness of visually generated VGI. Trans. GIS 2013, 17, 369-386. [CrossRef]

14. Gerlitz, C.; Rieder, B. Mining one percent of Twitter: Collections, baselines, sampling. M/C J. 2013, 16, 620.

15. Frank, M.; Dong, B.; Felt, A.P.; Song, D. Mining permission request patterns from Android and Facebook applications. In Proceedings of the 2012 IEEE 12th International Conference on Data Mining, Brussels, Belgium, 10-13 December 2012.

16. Zheng, Y.-T.; Zha, Z.-J.; Chua, T.-S. Mining travel patterns from geotagged photos. ACM Trans. Intell. Syst. Technol. 2012, 3, 56. [CrossRef]

17. Huang, W.; Li, S. Understanding human activity patterns based on space-time-semantics. ISPRS J. Photogramm. Remote Sens. 2016, 121, 1-10. [CrossRef]

18. Li, L.; Goodchild, M.F.; Xu, B. Spatial, temporal, and socioeconomic patterns in the use of Twitter and Flickr. Cartogr. Geogr. Inf. Sci. 2013, 40, 61-77. [CrossRef]

19. Li, J.; Qin, Q.; Han, J.; Tang, L.-A.; Lei, K.H. Mining trajectory data and geotagged data in social media for road map inference. Trans. GIS 2015, 19, 1-18. [CrossRef] 
20. De Albuquerque, J.P.; Herfort, B.; Brenning, A.; Zipf, A. A geographic approach for combining social media and authoritative data towards identifying useful information for disaster management. Int. J. Geogr. Inf. Sci. 2015, 29, 667-689. [CrossRef]

21. Zook, M.; Graham, M.; Shelton, T.; Gorman, S. Volunteered geographic information and crowdsourcing disaster relief: A case study of the Haitian earthquake. World Med. Health Policy 2010, 2, 7-33. [CrossRef]

22. Peary, B.D.M.; Shaw, R.; Takeuchi, Y. Utilization of social media in the east Japan earthquake and tsunami and its effectiveness. J. Nat. Disaster Sci. 2012, 34, 3-18. [CrossRef]

23. Takahashi, B.; Tandoc, E.C., Jr.; Carmichael, C. Communicating on Twitter during a disaster: An analysis of tweets during Typhoon Haiyan in the Philippines. Comput. Hum. Behav. 2015, 50, 392-398. [CrossRef]

24. Pennington, C.; Freeborough, K.; Dashwood, C.; Dijkstra, T.; Lawrie, K. The National Landslide Database of Great Britain: Acquisition, communication and the role of social media. Geomorphology 2015, 249, 44-51. [CrossRef]

25. Brown, D.; Saito, K.; Spence, R.; Chenvidyakarn, T.; Adams, B.; Mcmillan, A.; Platt, S. Indicators for measuring, monitoring and evaluating post-disaster recovery. In Proceedings of the 6th International Workshop on Remote Sensing for Disaster Applications, Pavia, Italy, 11-12 September 2008.

26. Hoshi, T.; Murao, O.; Yoshino, K.; Yamazaki, F.; Estrada, M. Post-disaster urban recovery monitoring in Pisco after the 2007 Peru earthquake using satellite image. J. Disaster Res. 2014, 9, 1059.

27. Brown, D.; Saito, K.; Liu, M.; Spence, R.; So, E.; Ramage, M. The use of remotely sensed data and ground survey tools to assess damage and monitor early recovery following the 12.5.2008 Wenchuan earthquake in China. Bull. Earthq. Eng. 2012, 10, 741-764. [CrossRef]

28. Rathfon, D.; Davidson, R.; Bevington, J.; Vicini, A.; Hill, A. Quantitative assessment of post-disaster housing recovery: A case study of Punta Gorda, Florida, after Hurricane Charley. Disasters 2013, 37, 333-355. [CrossRef] [PubMed]

29. McCarthy, K.; Hanson, M. Technical Report: Post-Katrina Recovery of the Housing Market along the Mississippi Gulf Coast; Gulf States Policy Institute: New Orleans, LA, USA, 2008.

30. The International Charter. Available online: https://www.disasterscharter.org/documents/10180/187832/ CHARTER_UA_ENG.pdf (accessed on 16 March 2017).

31. Goodchild, M.F.; Li, L. Assuring the quality of volunteered geographic information. Spat. Stat. 2012, 1, 110-120. [CrossRef]

32. Haklay, M.; Basiouka, S.; Antoniou, V.; Ather, A. How many volunteers does it take to map an area well? The validity of Linus' law to volunteered geographic information. Cartogr. J. 2010, 47, 315-322. [CrossRef]

33. Create Space Time Cube. Available online: http://pro.arcgis.com/en/pro-app/tool-reference/space-timepattern-mining/create-space-time-cube.htm (accessed on 27 December 2016).

34. Wiens, J.A.; Stralberg, D.; Jongsomjit, D.; Howell, C.A.; Snyder, M.A. Niches, models, and climate change: Assessing the assumptions and uncertainties. Proc. Natl. Acad. Sci. USA 2009, 106, 19729-19736. [CrossRef] [PubMed]

35. Hamed, K.H. Trend detection in hydrologic data: The Mann-Kendall trend test under the scaling hypothesis. J. Hydrol. 2008, 349, 350-363. [CrossRef]

36. Imran, M.; Castillo, C.; Lucas, J.; Meier, P.; Vieweg, S. AIDR: Artificial intelligence for disaster response. In Proceedings of the 23rd International Conference on World Wide Web, Seoul, Korea, 7-11 April 2014.

37. When to Go and Weather. Available online: http://www.lonelyplanet.com/philippines/weather (accessed on 21 December 2016).

38. Lagmay, A.M.F.; Eco, R. Brief communication: On the source characteristics and impacts of the magnitude 7.2 Bohol earthquake, Philippines. Nat. Hazards Earth Syst. Sci. 2014, 14, 2795-2801. [CrossRef]

39. Lagmay, A.M.F.; Agaton, R.P.; Bahala, M.A.C.; Briones, J.B.L.T.; Cabacaba, K.M.C.; Caro, C.V.C.; Dasallas, L.L.; Gonzalo, L.A.L.; Ladiero, C.N.; Lapidez, J.P.; et al. Devastating storm surges of Typhoon Haiyan. Int. J. Disaster Risk Reduct. 2015, 11, 1-12. [CrossRef]

40. The Bohol Quake: Then and Now (How Has Bohol's Recovered after this Disaster?). Available online: http:/ / 8list.ph/bohol-quake-third-anniversary/ (accessed on 10 December 2016).

41. A Year after Yolanda: Malapascua, Bantayan Now Ready for Tourists. Available online: http://www.philstar. com/cebu-business/2014/11/08/1389447/year-after-yolanda-malapascua-bantayan-now-ready-tourists (accessed on 10 December 2016). 
42. Tachikawa, T.; Kaku, M.; Iwasaki, A.; Gesch, D.B.; Oimoen, M.J.; Zhang, Z.; Danielson, J.J.; Krieger, T.; Curtis, B.; Haase, J.; et al. Aster Global Digital Elevation Model Version 2-Summary of Validation Results; NASA Land Processes Distributed Active Archive Center and the Joint Japan-US ASTER Science Team: Sioux Falls, SD, USA, 2011.

43. USGS Earthexplorer. Available online: https:/ / earthexplorer.usgs.gov/ (accessed on 23 December 2016).

44. OpenStreetMap. org.ph Mina-Mapa ang Pilipinas. Available online: https://openstreetmap.org.ph/ (accessed on 23 December 2016).

45. Humanitarian OpenStreetMap Team. Available online: https://hotosm.org/projects/typhoon_haiyan (accessed on 23 December 2016).

46. Gocotano, A.; Geroy, L.S.; Alcido, M.R.; Dorotan, M.M.; Balboa, G.; Hall, J.L. Is the response over? The transition from response to recovery in the health sector post-Typhoon Haiyan. West. Pac. Surveill. Response 2015, 6, 5-9. [CrossRef] [PubMed]

47. Philippine Tourism Continues. Available online: http://tourism.gov.ph/Pages/ 20131118aPHILIPPINETOURISMCONTINUES.aspx (accessed on 10 March 2017).

48. Bohol Earthquake Recovery Operation Comes to an End; Boholanos Grateful for Repaired Shelter, New Homes. Available online: http://reliefweb.int/report/philippines/bohol-earthquake-recoveryoperation-comes-end-boholanos-grateful-repaired-shelter (accessed on 9 March 2017).

49. After Typhoon Haiyan, Australians Help Philippines with Recovery. Available online: http:/ /www.smh. com.au/world/after-typhoon-haiyan-australians-help-philippines-with-recovery-20140912--10eule.html (accessed on 9 March 2017).

50. Look: Bohol's Centuries-old Churches Two Years after the Quake. Available online: http:/ /lifestyle.inquirer. net/198313/look-bohols-centuries-old-churches-two-years-after-the-quake/ (accessed on 10 March 2017).

51. 2 Centuries-old Bohol Churches Devastated by 7.2 Magnitude Earthquake. Available online: http:// newsinfo.inquirer.net/507125/centuries-old-baclayon-church-damaged-by-7-2-magnitude-quake (accessed on 15 December 2016).

52. Feick, R.; Roche, S. Understanding the value of VGI. In Crowdsourcing Geographic Knowledge: Volunteered Geographic Information (VGI) in Theory and Practice; Sui, D., Elwood, S., Goodchild, M., Eds.; Springer: Dordrecht, The Netherlands, 2013; pp. 15-29.

(C) 2017 by the authors. Licensee MDPI, Basel, Switzerland. This article is an open access article distributed under the terms and conditions of the Creative Commons Attribution (CC BY) license (http:/ / creativecommons.org/licenses/by/4.0/). 